\title{
EVALUATION OF BIOACTIVITIES OF MORINDA TINCTORIA LEAVES EXTRACT FOR PHARMACOLOGICAL APPLICATIONS
}

\author{
THANGAVEL SIVAKUMAR ${ }^{1}$, BHAGAVATHI SUNDARAM SIVAMARUTHI'², KAMARAJ LAKSHMI PRIYA ${ }^{1}$, \\ PERIYANAINA KESIKA ${ }^{2}$, CHAIYAVAT CHAIYASUT ${ }^{2 *}$
}

\begin{abstract}
${ }^{1}$ Department of Microbiology, Ayya Nadar Janaki Ammal College (Autonomous), Sivakasi, Tamil Nadu, India. ${ }^{2}$ Innovation Center for Holistic Health, Nutraceuticals, and Cosmeceuticals, Faculty of Pharmacy, Chiang Mai University, Chiang Mai-50200, Thailand. Email: chaiyavat@gmail.com
\end{abstract}

Received: 25 July 2017, Revised and Accepted: 30 October 2017

ABSTRACT

Objective: The present study was aimed to prepare Morinda tinctoria leaves extracts with the different solvent system and to evaluate the bioactivities.

Methods: The extracts of M. tinctoria were qualitatively analyzed for the primary phytochemical content. The functional groups of extract were determined by Fourier-transform infrared spectroscopy (FT-IR) analysis. The antimicrobial properties were determined by plate assays. The antioxidant and in vitro antiinflammatory properties and membrane stabilizing nature of aqueous extract of M. tinctoria (AEM) were measured using a spectrophotometer.

Results: The aqueous, ethanolic, and acetone extracts of M. tinctoria were prepared. AEM contains quinones, steroids, terpenoids, phenols, glycosides, and tannins. FTIR result showed that AEM comprises of alkyl halides, $1^{\circ}, 2^{\circ}$ amines, aromatics, aliphatic amines, alcohols, carboxylic acids, esters, ethers, and alkanes, saturated aliphatic, and phenolic groups. The antimicrobial property of M. tinctoria varied based on the solvent used for the extraction. About $86.90 \pm 0.36,78.58 \pm 0.13$, and $80.33 \pm 0.09 \%$ of total antioxidant capacity, reducing power, and hydrogen peroxide scavenging activity were observed in AEM, respectively. The 1, 1- diphenyl 2-picrylhyorazyl and 2, 2-Azinobis-(3 ethylbenzothiazoline-6-sulfonic acids) assay results indicated $85.20 \pm 0.50$ and $52.41 \pm 0.60 \%$ of free radical scavenging activity in AEM. The protease activity $(44.10 \pm 0.26 \%)$ and protein degradation $(44.38 \pm 0.58 \%)$ were proscribed by AEM. AEM prevents $69.36 \pm 0.20 \%$ of cell lysis.

Conclusion: The results revealed that the AEM leaves were harmless and enriched with potent bioactive principles, which is further used for food and pharmacological applications.

Keywords: Antimicrobial, Antioxidant, Anti-inflammation, Aqueous extraction, Morinda tinctoria.

(c) 2018 The Authors. Published by Innovare Academic Sciences Pvt Ltd. This is an open access article under the CC BY license (http://creativecommons. org/licenses/by/4. 0/) DOI: http://dx.doi.org/10.22159/ajpcr.2018.v11i2.21583

\section{INTRODUCTION}

The kingdom Plantae contains about 300-315 thousands of plant species, and many of them are used as medicines for years. The species of Morinda genus are one of the ethnic plants of tropical countries and are used in folk medicine since ages. Morinda tinctoria, commonly known as Nunaa, is grown in several parts of Southeast Asia, especially in the agricultural lands and unrefined lands. Even though the use and prescription of the synthetic drug are increased remarkably, about $20-25 \%$ of active drug compounds were directly derived from the plants [1]. M. citrifolia is known for the medicinal and nutritional values. M. citrifolia fruit juices have been used an alternative medicine for the treatment of arthritis, diabetes, muscle aches, menstrual complications, cancers, gastric ulcer, heart disease, and drug addiction. Apart from fruits, leaves and roots of $M$. tinctoria are used as astringent and deobstruent $[2,3]$.

The intervention of ethyl acetate extract of $M$. tinctoria significantly reduces the glucose level, $\mathrm{HbA1C}$, and lipid profile and increases C-peptide and plasma insulin in alloxan-induced diabetic rats, and the hepatoprotective and hypoglycemic effect of M. tinctoria was comparable to glibenclamide. Moreover, authors claimed that the ethyl acetate extract showed more promising results than the ethanol extract of M. tinctoria (EEM), which indicates that the extracting solvents are influencing the active content of the extract [4]. M. tinctoria leaves ashes are reported to act as a biosorbents in regulating ammonia pollution in wastewater management [5]. A batch biosorption system study revealed that the seeds of $M$. tinctoria were the potent remover of reactive red-198 dye from an aqueous solution [6]. Kumaresan and Saravanan [3] investigated the in vivo anticonvulsant activity of $M$. tinctoria using albino mice and found that $M$. tinctoria extracts improved the diseased condition. Vadivu et al. [7] assessed the antiulcer activity of EEM Roxb. leaves using induced gastric ulcer models in rats, and M. tinctoria extract significantly reduced the gastric volume, free acidity, and total acidity.

The administration of methanol extract of $M$. tinctoria in carbon tetrachloride intoxicated rats improved the host health by revoking the serum glutamate oxaloacetate transaminase, serum glutamate pyruvate transaminase, alkaline phosphatase, and total protein and bilirubin levels. The pharmacological influences were also proved by histological studies [8]. The larvicidal, adulticidal, and ovicidal activities of M. tinctoria were also reported against Anopheles stephensi [9]. Several scientific reports revealed the antimicrobial activity of $M$. tinctoria extracts. The bioactivities of any medicinal plant may vary due to the extraction methods, solvent used, and cultivars of the plant.

Although several studies explained about the phytochemical content and bioactivities of $M$. tinctoria, more scientific knowledge is in need to explore the pharmacological nature of the plant. Thus, the present study was designed to extract $M$. tinctoria leaves with different solvent system and to evaluate the bioactivities like antimicrobial property against human pathogens and in vitro anti-inflammatory activity. 


\section{METHODS}

\section{Sample collection and extraction}

The fully matured fresh leaves of $M$. tinctoria were collected from a local area in Sivakasi, Tamil Nadu. The leaves were washed thoroughly, shade dried, and finely powdered for further use. The dried powdered leaves were extracted with three different solvents such as water, acetone, and ethanol separately. The extracts were prepared by mixing $10 \mathrm{~g}$ of powdered leaf samples with $100 \mathrm{ml}$ of each solvent separately and incubated in a mechanical shaker for $48 \mathrm{~h}$ at room temperature. After the incubation period, the contents were filtered through Whatman No.1 filter paper, and the filtered solution was concentrated by evaporating the solvents, dried, and was stored in the refrigerator at $4^{\circ} \mathrm{C}$ until further use [10].

\section{Phytochemical analysis}

The qualitative screening of leaf extracts of M. tinctoria was performed for the identification of various classes of active chemical constituents such as alkaloids, betacyanins, quinones, glycosides, tannins, terpenoids, phenols, volatile oils, and steroids using standard procedures. The method employed to analyze the phytochemicals are described by Ruskin et al. [11].

\section{Fourier-transform infrared spectroscopy (FTIR)}

A single-beam FTIR spectrometer (FT-IR 8400S, Shimadzu) was used to analyze the extract by following the standard $\mathrm{KBr}$ method [12]. An average of 32 scans was figured with a spectral range of $400-4000 \mathrm{~cm}^{-1}$ at $4 \mathrm{~cm}^{-1}$ resolution.

\section{Antimicrobial activity of $M$. tinctoria extract}

Dried EEM and acetone extract of $M$. tinctoria (AcEM) are dissolved in distilled water with $<0.2 \%$ of respective solvents (ethanol and acetone) and stored at $4^{\circ} \mathrm{C}$ until use for antimicrobial assay. The antimicrobial property of the extract was evaluated against representative bacteria (Escherichia coli, Serratia sp., Bacillus sp., Streptococcus sp., Klebsiella sp., Bacillus megaterium, Shigella sp., and Pseudomonas aeruginosa) and fungal (Candida albicans and Fusarium sp.) species by agar-well diffusion method as described by Ruskin et al. [11]. Nutrient agar medium and potato dextrose agar medium were used for bacterial and fungal growth, respectively.

\section{Assessment of antioxidant activities}

Total antioxidant capacity (TAC) [13], reducing power [14], and hydrogen peroxide scavenging activity [15] of $M$. tinctoria aqueous extract were assessed as prescribed earlier. The free radical scavenging assays such as 1, 1- diphenyl 2-picrylhyorazyl (DPPH) and 2, 2-Azinobis-(3 ethylbenzothiazoline-6-sulfonic acids) (ABTS) were performed to determine the free radical scavenging property of M. tinctoria extract as detailed in the previous studies [15-17].

Inhibition of protein denaturation and protease inhibition assay Inhibition of protein denaturation and protease inhibition assays were performed as described by Reshma et al. [18]. Acetylsalicylic acid was used as a positive control. The experiment was carried out in triplicates, and the results were expressed as a percentage of inhibition.

\section{Membrane stabilization test}

Blood was collected from a healthy human volunteer. The collected blood was mixed with equal volume of sterilized Alsever's solution ( $2 \%$ dextrose, $0.8 \%$ sodium citrate, $0.5 \%$ citric acid, and $0.42 \%$ sodium chloride in water) and was centrifuged at $3000 \mathrm{rpm}$ for $15 \mathrm{~min}$. The supernatants were carefully removed while the packed red blood cell was washed with isosaline $\left(0.85 \% \mathrm{NaCl}_{2} \mathrm{pH} 7.2\right)$. The process of washing and centrifugation was repeated until getting a clear supernatant, and a $10 \%(\mathrm{v} / \mathrm{v})$ suspension of saline red blood cells (SRBC) was made with isosaline. Then, $1 \mathrm{ml}$ of phosphate buffer $(0.15 \mathrm{M}, \mathrm{pH} 7.4), 2 \mathrm{ml}$ of hyposaline $\left(0.36 \% \mathrm{NaCl}_{2} \mathrm{pH} 7.2\right)$, and $0.5 \mathrm{ml}$ of SRBC suspension were mixed. Aspirin was used as reference drug. Instead of hyposaline, $2 \mathrm{ml}$ of distilled water was used in control. All the assay mixtures were incubated at $37^{\circ} \mathrm{C}$ for $30 \mathrm{~min}$ and centrifuged. The hemoglobin content in the supernatant was estimated using spectrophotometer at $560 \mathrm{~nm}$. The percentage inhibition of hemolysis was calculated as follows.

$\%$ inhibition of hemolysis $=100 \times\left(A_{1}-A_{2} / A_{1}\right)$.

Where $A_{1}=$ absorption of hypotonic buffered saline solution alone (control), and $A_{2}=$ absorption of the test sample in hypotonic solution [19].

\section{Statistical analysis}

The experiments were performed in triplicates. The results were denoted as a mean \pm standard deviation. Statistical analysis was executed using one-way analysis of variance (SPSS version 17 statistical software [Chicago, SPSS Inc., U.S.A]).

\section{RESULTS AND DISCUSSION}

\section{Phytochemicals and functional groups}

The extracts of $M$. tinctoria leaves were prepared using water, acetone, and ethanol as the solvent system. Aqueous extracted M. tinctoria (AEM) leaves were subjected to the qualitative analysis of significant phytochemicals. The results revealed that the AEM contains quinones, steroids, terpenoids, phenols, glycosides, and tannins, whereas betacyanins, alkaloids, and volatile oils are not observed in AEM (Table 1).

AEM was further analyzed by FTIR to reveal the functional groups present in the extract. The representative FT-IR spectrum of AEM leaves is shown in Fig. 1. The peak value, bonding information, and possible functional groups of the AEM were tabulated (Table 2). The functional groups were derived by comparing the previous literature and database

Table 1: Phytochemical investigation of M. tinctoria. (+) presence and (-) absence

\begin{tabular}{ll}
\hline Phytochemicals & AEM \\
\hline Quinones & + \\
Betacyanins & - \\
Alkaloids & - \\
Steroids & + \\
Terpenoids & + \\
Phenols & + \\
Glycosides & + \\
Volatile oils & - \\
Tannins & + \\
\hline
\end{tabular}

M. tinctoria: Morinda tinctoria

Table 2: Functional groups of the leaves extracts of $M$. tinctoria plant revealed by FTIR

\begin{tabular}{lll}
\hline $\begin{array}{l}\text { Peak } \\
\text { value }\left(\mathbf{c m}^{-1}\right)\end{array}$ & Bond & Class of compounds \\
\hline 517.85 & C-Br stretch & Alkyl halides \\
598.86 & C-Br stretch & Alkyl halides \\
666.36 & C-Br stretch & Alkyl halides \\
781.12 & C-Cl stretch & Alkyl halides \\
833.19 & N-H wag & $1^{\circ} 2^{\circ}$ amines \\
886.23 & C-H "oop" & Aromatics \\
1032.81 & C-N stretch & Aliphatic amines \\
1067.53 & C-N stretch & Aliphatic amines \\
1233.39 & C-H wag (-CH2X) & Alkyl halides \\
1318.25 & C-O stretch & Alcohols, carboxylic \\
& & acids, esters, ethers \\
1373.22 & C-H rock & Alkanes \\
1451.33 & C-H bond & Alkanes \\
1642.27 & N-H bond & $1^{\circ}$ amines \\
1741.6 & C=O stretch & Esters, saturated \\
& & aliphatic \\
2853.49 & C-H stretch & Alkanes \\
2924.85 & C-H stretch & Alkanes \\
3441.74 & O-H stretch, H-bonded & Alcohols, phenols \\
\hline
\end{tabular}

M. tinctoria: Morinda tinctoria, FTIR: Fourier-transform infrared spectroscopy 


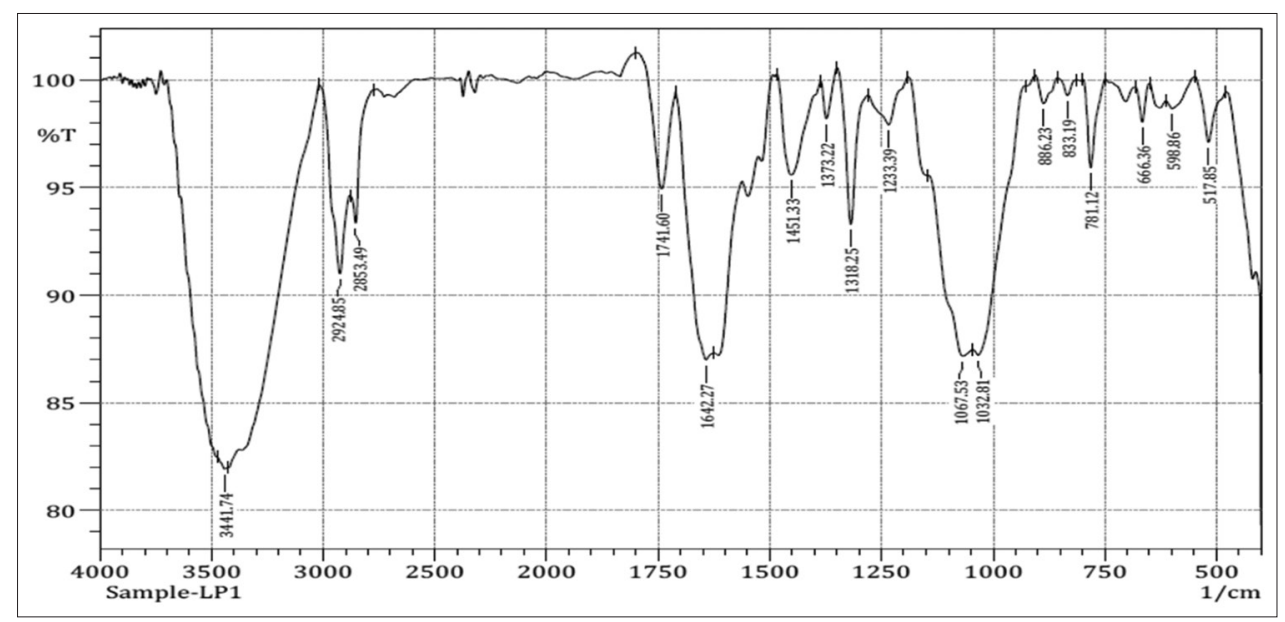

Fig. 1: The representative Fourier-transform infrared spectroscopy spectrum of aqueous extract of Morinda tinctoria leaves

Table 3: Antibacterial activities of AcEM

\begin{tabular}{|c|c|c|c|c|c|c|c|c|}
\hline \multirow{3}{*}{$\begin{array}{l}\text { Concentration } \\
(\mu \mathrm{g} / \mathrm{ml})\end{array}$} & \multicolumn{8}{|c|}{ Zone of inhibition (mm) } \\
\hline & \multicolumn{8}{|c|}{ Bacterial strains } \\
\hline & Serratia sp. & Bacillus sp. & Shigella sp. & B. megatrium & Klebsiella sp. & E. coli & P. aeruginosa & Streptococcus sp. \\
\hline Control (Acetone) & - & - & - & - & - & - & - & - \\
\hline 50 & - & 13 & 13 & - & 11 & - & 11 & 14 \\
\hline 75 & 15 & 16 & 14 & 14 & 13 & 15 & 15 & 18 \\
\hline 100 & 22 & 19 & 21 & 20 & 17 & 21 & 19 & 25 \\
\hline
\end{tabular}

of the instrument. The results suggested that AEM encloses alkyl halides, $1^{\circ}, 2^{\circ}$ amines, aromatics, aliphatic amines, alcohols, carboxylic acids, esters, ethers, and alkanes, saturated aliphatic, and phenolic groups (Table 2).

The studies revealed that the methanolic extract of M. tinctoria leaves yielded a high content of phenolic acids when compared to that of the chloroform, ethyl acetate, and hexane extract. The antioxidant studies suggested that the methanolic and ethyl acetate extract of M. tinctoria leaves acquired the more active principles than that of the other solvents $[20,21]$. The dried leaves of $M$. tinctoria have $31 \%$ of ash with 71 and $29 \%$ of acid-soluble and insoluble ashes, respectively. About $6 \%$ of tannin is found to be reported in M. tinctoria leaves [22]. Arunachalam et al. [23] also revealed the phytochemical content of M. tinctoria using high-performance liquid chromatography and gas chromatographymass spectrometry methods. FT-IR was performed in the current study, which is the primary report that revealed the functional groups of AEM.

\section{Antimicrobial property}

The antimicrobial property of AcEM leaves was assessed against human bacterial and fungal pathogens. Three different concentrations of AcEM (50, 75, and $100 \mu \mathrm{g} / \mathrm{ml}$ ) were used. Acetone was used as a control. AcEM showed antagonistic activity against Bacillus, Shigella, and Streptococcus species at low concentration, whereas in increased concentration, AcEM showed antimicrobial activity against all tested bacterial strains. About 22, 19, 21, 20, 17, 21, 19, and $25 \mathrm{~mm}$ of the zone of inhibitions were observed against Serratia sp., Bacillus sp., Shigella sp., B. megaterium, Klebsiella sp., E. coli, P. aeruginosa, and Streptococcus sp., respectively (Table 3). Likely, the antifungal activity of AcEM was observed against C. albicans $(19 \mathrm{~mm})$, and Fusarium sp. $(13 \mathrm{~mm})$ at high concentration of extract $(100 \mu \mathrm{g} / \mathrm{ml})$, while no activity was observed at low concentration $(50 \mu \mathrm{g} / \mathrm{ml}$ ) (Table 4).

EEM exhibited antagonistic activity against Serratia sp., Bacillus sp., Shigella sp., B. megaterium, and Klebsiella sp. at low concentration, whereas increased concentration of EEM showed antimicrobial
Table 4: Antifungal activities of AcEM

\begin{tabular}{lll}
\hline Concentration $(\mu \mathrm{g} / \mathrm{ml})$ & \multicolumn{2}{l}{ Zone of inhibition $(\mathrm{mm})$} \\
\cline { 2 - 3 } & \multicolumn{2}{l}{ Fungal strains } \\
\cline { 2 - 3 } & C. albicans & Fusarium sp. \\
\hline Control (acetone) & - & - \\
50 & - & - \\
75 & 14 & 10 \\
100 & 19 & 13 \\
\hline
\end{tabular}

AcEM: Acetone extract of Morinda tinctoria, C. albicans: Candida albicans

activity against all tested bacterial strains. About 18, 20, 23, 22, 19, 22,24 , and $15 \mathrm{~mm}$ of the zone of inhibitions were observed against Serratia sp., Bacillus sp., Shigella sp., B. megaterium, Klebsiella sp., E. coli, P. aeruginosa, and Streptococcus sp., respectively (Table 5). Likely, the antifungal activity of EEM was observed against $C$. albicans $(21 \mathrm{~mm})$ and Fusarium sp. $(14 \mathrm{~mm})$ at high concentration of extract $(100 \mu \mathrm{g} / \mathrm{ml})$, while no activity was observed at low concentration $(50 \mu \mathrm{g} / \mathrm{ml})$ against Fusarium sp. (Table 6).

The different solvent extract of $M$. tinctoria leaves showed antibacterial (E. coli, Micrococcus luteus, Bacillus subtilis, and Bacillus cereus) and antifungal (Saccharomyces cerevisiae, Ustilago maydis, and Aspergillus niger) activity [24]. Kaniakumari et al. [25] reported the in vitro antimicrobial effect of crude extracts of $M$. tinctoria against Staphylococcus epidermidis, S. aureus, E. coli, Shigella flexneri, A. flavus, Mucor sp., C. albicans, Trichophyton mentagrophytes, and Microsporum gypseum.

The results of the zone of inhibition based antimicrobial evaluation of AcEM and EEM suggested that AcEM had the more active compounds against Serratia and Streptococcus species than that of the EEM, whereas EEM harbored bioactive compounds against Bacillus sp., Shigella sp., B. megatrium, Klebsiella sp., E. coli, and P. aeruginosa than that of 


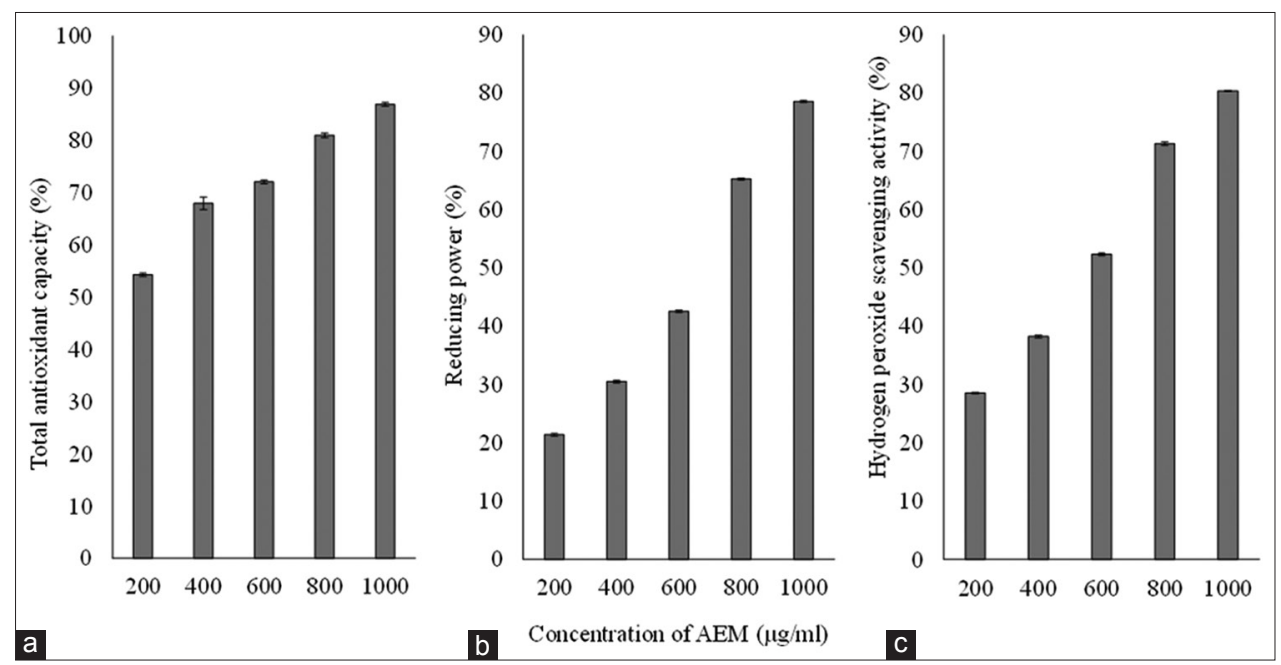

Fig. 2: The total antioxidant capacity (a), reducing power (b), and hydrogen peroxide scavenging activity (c) of aqueous extracted Morinda tinctoria leaves. The data (mean \pm standard deviation) were represented in percentage. The bioactivities of the extract were directly proportional to the concentration of extract

Table 5: Antibacterial activities of EEM

\begin{tabular}{|c|c|c|c|c|c|c|c|c|}
\hline \multirow{3}{*}{$\begin{array}{l}\text { Concentration } \\
(\mu \mathrm{g} / \mathrm{ml})\end{array}$} & \multicolumn{8}{|c|}{ Zone of inhibition (mm) } \\
\hline & \multicolumn{8}{|c|}{ Bacterial strains } \\
\hline & Serratia sp. & Bacillus sp. & Shigella sp. & B. megaterium & Klebsiella sp. & E. coli & P. aeruginosa & Streptococcus sp. \\
\hline $\begin{array}{l}\text { Control } \\
\text { (ethanol) }\end{array}$ & - & - & - & - & - & - & - & - \\
\hline 50 & 12 & 14 & 12 & 13 & 12 & - & - & - \\
\hline 75 & 14 & 17 & 15 & 17 & 14 & 17 & 14 & 11 \\
\hline 100 & 18 & 20 & 23 & 22 & 19 & 22 & 24 & 15 \\
\hline
\end{tabular}

EMM: Ethanol extract of Morinda tinctoria, B. megaterium: Bacillus megaterium, E. coli: Escherichia coli, P. aeruginosa: Pseudomonas aeruginosa

the AcEM (Tables 3 and 5). Moreover, EEM showed better antifungal activity against tested representative fungal species compared to that of the AcEM (Tables 4 and 6).

\section{Antioxidant activity}

The antioxidant properties of AEM have been assessed by TAC, reducing power, hydrogen peroxide scavenging activity, DPPH, and ABTS assay. Five different concentrations of AEM $(200,400,600,800$, and $1000 \mu \mathrm{g} / \mathrm{ml}$ ) were used for the study. The range of $54.26 \pm 0.34-$ $86.90 \pm 0.36 \%$ of TAC was observed in AEM samples. About $21.40 \pm 0.20-$ $78.58 \pm 0.13 \%$ of reducing power was noted in the extract. In both TAC and reducing power study, ascorbic acid was considered as a positive control. AEM showed about $28.55 \pm 0.11-80.33 \pm 0.09 \%$ of hydrogen peroxide scavenging activity, and gallic acid was used as positive control (Fig. 2). The DPPH and ABTS assay results showed about 46.18 $\pm 0.43-$ $85.20 \pm 0.50$ and $27.43 \pm 0.55-52.41 \pm 0.60 \%$ of free radical scavenging activity in AEM samples, respectively (Fig. 3).

The specific antioxidant property and its mechanism have not been explored in M. tinctoria. A study by Kolli et al. revealed that the hexane extract of M. tinctoria leaves had $91.2 \pm 0.05 \%$ of free radical scavenging ability in DPPH assay, whereas the ethyl acetate extract displayed only $65.1 \pm 0.05 \%$ of activity [20].

The results of the present study revealed the antioxidant ability of an AEM leaves in various in vitro models. The free radical scavenging ability was found to be altered based on the concentration and also affected by the extraction method.

\section{Anti-inflammatory property of AEM}

The protease inhibition and the prevention of protein degradation activity of AEM were measured, and the results were represented as a percentage of inhibition. About $44.10 \pm 0.26 \%$ of protease inhibition activity was
Table 6: Antifungal activities of EEM

\begin{tabular}{lll}
\hline Concentration $(\mu \mathrm{g} / \mathrm{ml})$ & \multicolumn{2}{l}{ Zone of inhibition $(\mathbf{m m})$} \\
\cline { 2 - 3 } & \multicolumn{2}{l}{ Fungal strains } \\
\cline { 2 - 3 } & C. albicans & Fusarium sp. \\
\hline Control (ethanol) & - & - \\
50 & 13 & - \\
75 & 16 & 11 \\
100 & 21 & 14 \\
\hline
\end{tabular}

EMM: Ethanol extract of Morinda tinctoria, C. albicans: Candida albicans

exhibited by $100 \mu \mathrm{g} / \mathrm{ml}$ of AEM. Likely, $44.38 \pm 0.58 \%$ of inhibition of protein degradation was exhibited by AEM (Fig. 4). The membrane stabilizing property of AEM was evaluated using red blood cells lysis assay. The results showed that the AEM stabilizes the red blood cell membrane by exhibiting about $69.36 \pm 0.20 \%$ inhibition of cell lysis (Fig. 5).

The ethanolic extract of $M$. tinctoria leaves nullified the aspirin pyloric ligation-induced gastric and cysteamine-induced duodenal ulceration at the concentration of $200-400 \mathrm{mg} / \mathrm{kg}$ in rats. The volume and acidity of gastric juice in pyloric ligated rats were reduced on supplementation of ethanolic extract of $M$. tinctoria. Moreover, M. tinctoria supplementation significantly minimizes the number of ulcers in both pyloric ligation-induced gastric and cysteamine-induced duodenal ulcer in vivo models [26]. The hepatoprotective nature of M. tinctoria was demonstrated in D-galactosamine-induced liver damaged rats. The level of serum markers (alanine aminotransferase and aspartate aminotransferase) was reduced, and the antioxidant level was increased significantly on M. tinctoria intervention to the liver damaged rats [27]. 


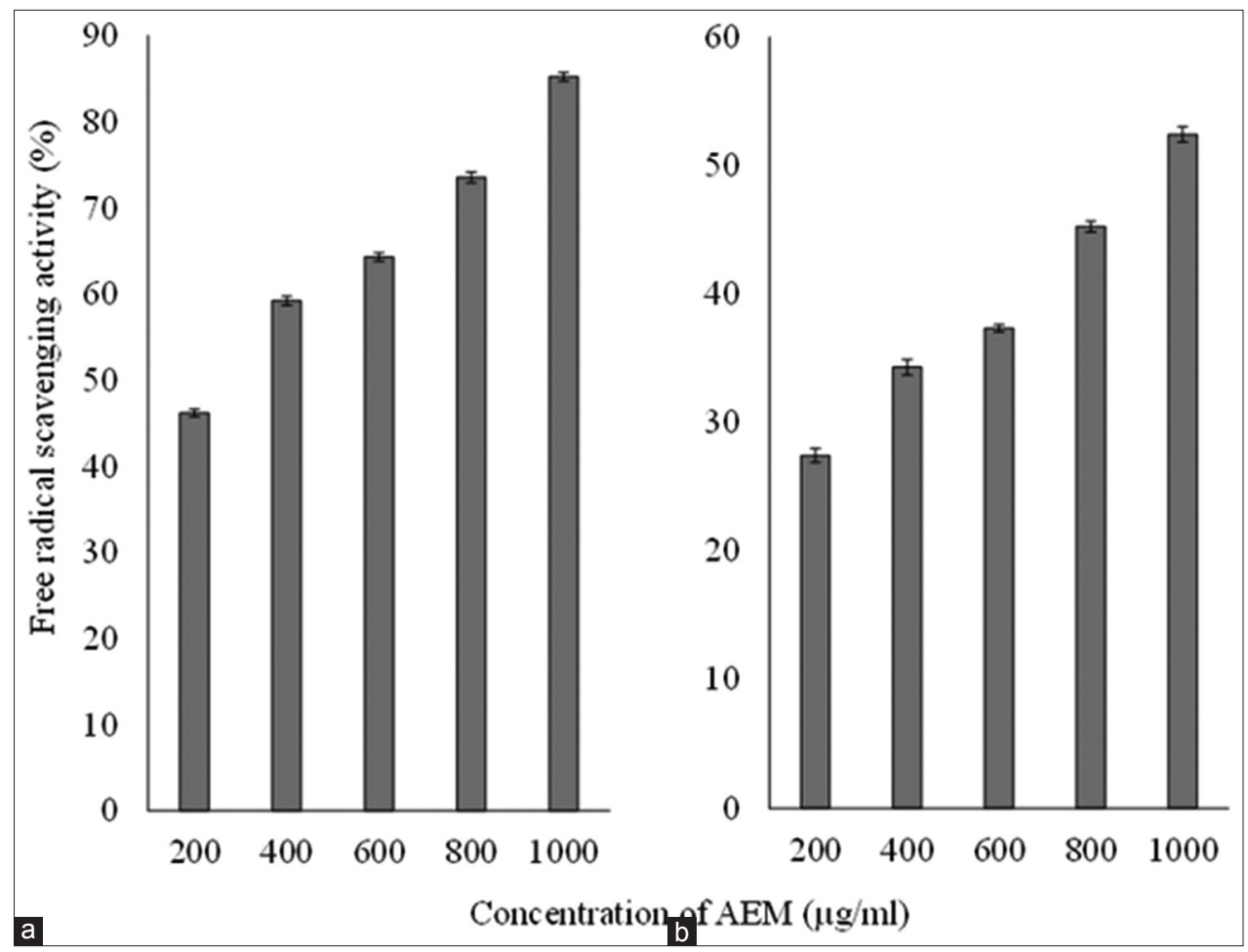

Fig. 3: The free radical scavenging activity profile of aqueous extracted Morinda tinctoria leaves in 1, 1-diphenyl 2-picrylhyorazyl (a) and 2, 2-Azinobis-(3 ethylbenzothiazoline-6-sulfonic acids) (b) assays

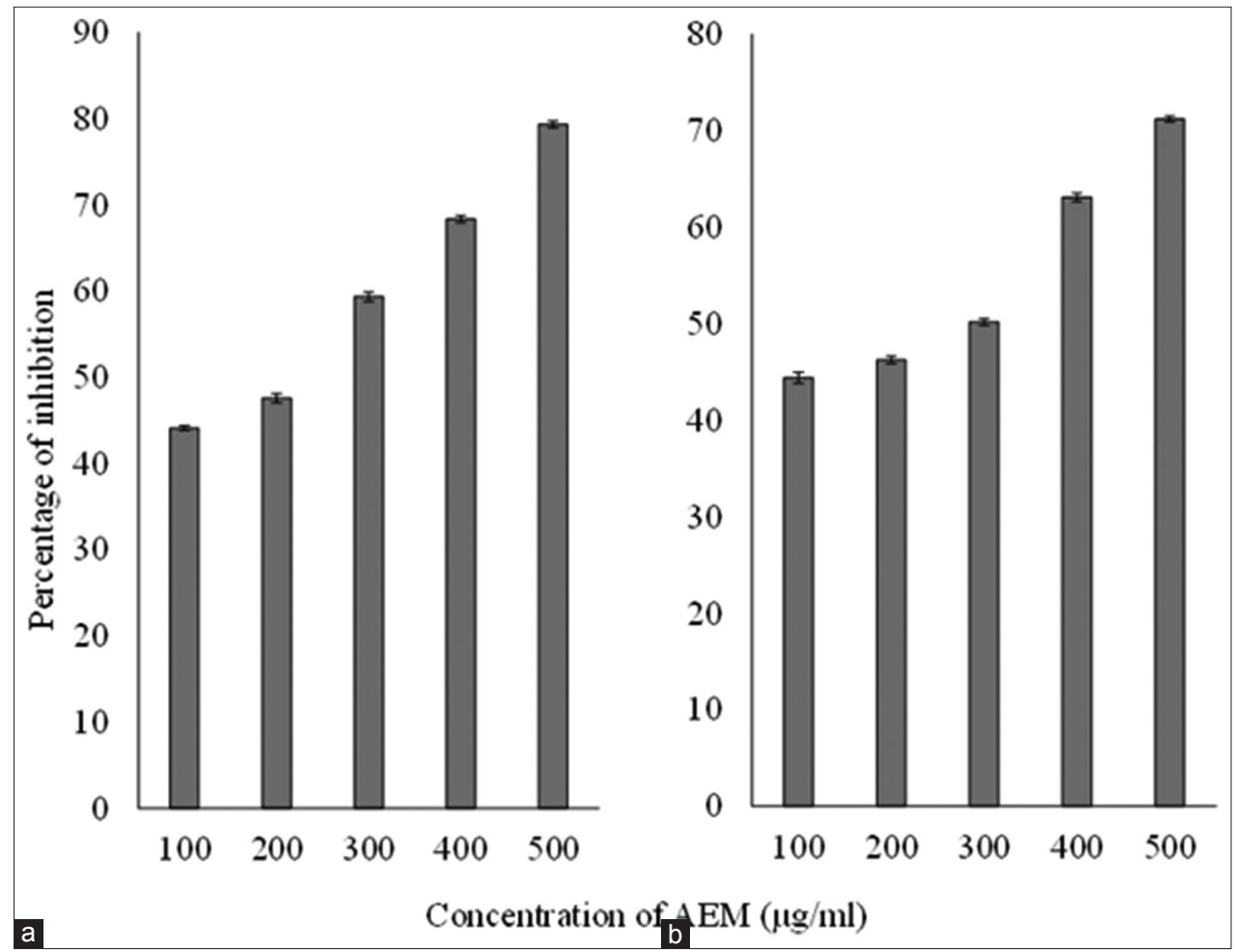

Fig. 4: The protease inhibiting power (a) and prevention of protein degradation property (b) of aqueous extracted Morinda tinctoria leaves

In the present study, in vitro anti-inflammatory property of $M$. tinctoria extract was estimated by evaluating the protease inhibition and prevention of protein denaturation properties. The results suggested that the experimental extract (AEM) was potent enough to inhibit the protease activity up to $44 \%$ and also prevent the protein degradation effectively. The membrane stabilizing property of $M$. tinctoria was not yet reported. The results of the current study revealed that $M$. tinctoria was a promising candidate to protect the membrane damages. 


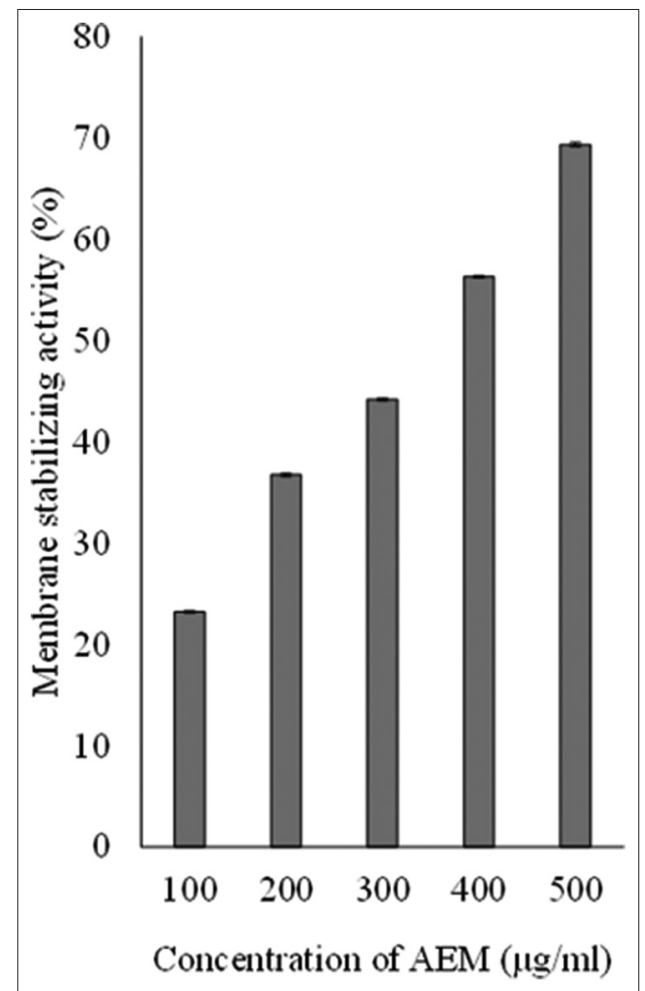

Fig. 5: The membrane stabilizing potential of aqueous extracted Morinda tinctoria leaves

\section{CONCLUSION}

The AEM extract comprises of quinones, steroids, terpenoids, phenols, glycosides, and tannins. The AEM showed better antioxidant and antiinflammatory properties in tested in vitro models. Ethanolic extract of M. tinctoria leaves contains more bioactive principles, which act against the representative human pathogens. Moreover, the results showed that the organic solvent-free extraction method could achieve potent extract with bioactive principles, which is further used for food and pharmacological applications.

\section{ACKNOWLEDGMENT}

TS and KLP acknowledge the Department of Microbiology, Ayya Nadar Janaki Ammal College, Tamil Nadu, India, for the instrumentation, laboratory, and financial support. BSM, PK, and CC thankfully acknowledge Chiang Mai University grant (CMU-grant) for the support and also gratefully acknowledge the Faculty of Pharmacy, and Chiang Mai University, Thailand.

\section{AUTHORS CONTRIBUTIONS}

BSS and PK contributed to Study design, manuscript preparation and critical revision of the manuscript. TS, and KL responsible for wet lab experiments, data collection, and analysis. CC involved in the review and finalization of the manuscript. All the authors agree with the content of the manuscript.

\section{CONFLICT OF INTEREST}

There is no conflict of interests.

\section{REFERENCES}

1. Newman DJ, Cragg GM, Snader KM. The influence of natural products upon drug discovery. Nat Prod Rep 2000;17:215-34.

2. Wang MY, West BJ, Jensen CJ, Nowicki D, Su C, Palu AK, et al. Morinda citrifolia (Noni): A literature review and recent advances in noni research. Acta Pharmacol Sin 2002;23:1127-41.

3. Kumaresan PT, Saravanan A. Anticonvulsant activities of Morinda tinctoria Roxb. Afr J Pharm Pharmacol 2009;3:63-5.

4. Ramasubramanian V, Palanivelu K. Biochemical and histopathological changes on alloxan induced diabetic albino rats treated with leaves of Morinda tinctoria Roxb. Int J Curr Med Pharm Res 2016;2:316-22.

5. Suneetha M, Ravindhranath K. New bio-sorbents in controlling ammonia pollution in wastewaters. J Chem Pharm Res 2012;4:526-37.

6. Vijayalakshmi R, Venkatachalam R, Periyathambi T, Saravanan P. Biosorption of reactive red 198 from an aqueous solution using Morinda tinctoria. IJRTSAT 2013;9:36-40.

7. Vadivu R, Chitra V, Susmitha, Sindhu K, Muthusamy P, Suseela L. The effect of ethanol extract of Morinda tinctoria Roxb leaves on antiulcer activity in rats. NPAIJ 2008;4:99-102.

8. Sait II, Harindran J, Vahab AA, Jeena JL, Nasli S, John J. Potential hepatoprotective effect and antioxidant role of methanol extract of Morinda tinctoria in carbon tetrachloride induced hepatotoxicity in albino rats. Int J Pharm 2014;4:363-8.

9. Amerasan D, Murugan K, Panneerselvam C, Kanagaraju N, Kovendan K, Mahesh KP. Bioefficacy of Morinda tinctoria and pongamiaglabra plant extracts against the malaria vector Anopheles stephensi (Diptera: Culicidae). J Entomol Acarol Res 2015;47:31-40.

10. Kumar SN, Simon KN, Parvathy B. In vitro antimicrobial activities and phytochemical analysis of Morinda tinctoria (L) leaf extracts. Int J Pharm Sci Rev Res 2016;38:58-61.

11. Ruskin RS, Kumari BV, Chitarasu T. Qualitative phytochemical and FTIR analysis of root extracts of Canthium parviflorum Lam. J Chem Pharm Sci 2014;2:122-7.

12. Pengkumsri N, Sivamaruthi BS, Sirilun S, Peerajan S, Kesika P, Chaiyasut $\mathrm{K}$, et al. Extraction of $\beta$-glucan from Saccharomyces cerevisiae: Comparison of different extraction methods and in vivo assessment of immunomodulatory effect in mice. Food Sci Technol (Campinas) 2017;37:124-30.

13. Prieto P, Pineda M, Aguilar M. Spectrophotometric quantitation of antioxidant capacity through the formation of a phosphomolybdenum complex: Specific application to the determination of Vitamin E1. Anal Biochem 1999;269(2):337-41.

14. Shahriar M, Hossain MD, Sharmin AF, Akhter S, Haque MD, Bhuiyan MA. In vitro antioxidant and free radical scavenging activity of Withania somnifera root. IOSR J Pharm 2013;3:38-47.

15. Peerajan S, Chaiyasut C, Sirilun S, Chaiyasut K, Kesika P, Sivamaruthi BS. Enrichment of nutritional value of Phyllanthus emblica fruit juice using the probiotic bacterium, Lactobacillus paracasei HII01 mediated fermentation. Food Sci Technol (Campinas) 2016;36:116-23.

16. Pengkumsri N, Chaiyasut C, Saenjum C, Sirilun S, Peerajan S, Suwannalert $\mathrm{P}$, et al. Physicochemical and antioxidative properties of black, brown and red rice varieties of northern Thailand. Food Sci Technol (Campinas) 2015;35:331-8.

17. Chaiyasut C, Sivamaruthi BS, Pengkumsri N, Sirilun S, Peerajan S, Chaiyasut $\mathrm{K}$, et al. Anthocyanin profile and its antioxidant activity of widely used fruits, vegetables, and flowers in Thailand. Asian J Pharm Clin Res 2016;9:218-24.

18. Reshma, Arun KP, Brindha P. In vitro anti-inflammatory, antioxidant and nephroprotective studies on leaves of Aegle marmelos and Ocimum sanctum. Asian J Pharm Clin Res 2014;7:121-9.

19. Rajalakshmi GR, Jyoti H. Anti-Inflammatory activity of Wrightia tinctoria leaves by membrane stabilization. Int J Pharm Sci Res 2012;3:497-9.

20. Kolli D, Amperayani KR, Parimi U. Total phenolic content and antioxidant activity of Morinda tinctoria leaves. Indian J Pharm Sci 2015;77:226-30.

21. Sreena KP, Poongothai A, Soundariya SV, Srirekha G, Santhi R, Annapoorani S. Evaluation of in vitro free radical scavenging efficacy of different organic extracts of Morinda tinctoria leaves. Int J Pharm Pharm Sci 2011;3 Suppl 3:207-9.

22. Shanthi G, Saridha D, Mariappan V. Pharmacognostical studies on Morinda tinctoria. Roxb. Int J Pharm Pharm Sci 2012;4:636-8.

23. Arunachalam KD, Kuruva JK, Hari S, Annamalai SK, Baskaran KV. HPTLC finger print analysis and phytochemical investigation of Morinda tinctoria Roxb leaf extracts by HPLC and GS MS. Int J Pharm Pharm Sci 2015;7:360-6.

24. Jayasinghe UL, Jayasooriya CP, Bandara BM, Ekanayake SP, Merlini L, Assante $\mathrm{G}$, et al. Antimicrobial activity of some Sri Lankan Rubiaceae and Meliaceae. Fitoterapia 2002;73:424-7.

25. Kaniakumari D, Selvakumar P, Loganathan V. In vitro antibacterial and antifungal activities of Morinda tinctoria leaf in different solvents. Pharmacia 2013;2:52-8.

26. Sivaraman D, Muralidharan P. Cytoprotective effect of Morinda tinctoria Roxb. Against surgical and chemical factor induced gastric and duodenal ulcers in rats. Ulcers 2011;2011:1-9.

27. Surendiran G, Mathivanan N. Hepatoprotective properties of Morinda pubescens J.E. Smith (Morinda tinctoria Roxb.) fruit extract. Med Chem Res 2011;20:307-13 